\title{
Intercalation of lithium into disordered graphite in a working battery
}

\author{
Johnsen, Rune E.; Norby, Poul; Leoni, Matteo
}

Published in:

Journal of Applied Crystallography

Link to article, DOI:

$10.1107 / \mathrm{S} 1600576718007756$

Publication date:

2018

Document Version

Publisher's PDF, also known as Version of record

Link back to DTU Orbit

Citation (APA):

Johnsen, R. E., Norby, P., \& Leoni, M. (2018). Intercalation of lithium into disordered graphite in a working battery. Journal of Applied Crystallography, 51(4), 998-1004. https://doi.org/10.1107/S1600576718007756

\section{General rights}

Copyright and moral rights for the publications made accessible in the public portal are retained by the authors and/or other copyright owners and it is a condition of accessing publications that users recognise and abide by the legal requirements associated with these rights.

- Users may download and print one copy of any publication from the public portal for the purpose of private study or research.

- You may not further distribute the material or use it for any profit-making activity or commercial gain

- You may freely distribute the URL identifying the publication in the public portal

If you believe that this document breaches copyright please contact us providing details, and we will remove access to the work immediately and investigate your claim 


\title{
Intercalation of lithium into disordered graphite in a working battery
}

\author{
Rune E. Johnsen, Poul Norby and Matteo Leoni
}

J. Appl. Cryst. (2018). 51, 998-1004

\section{IUCr Journals CRYSTALLOGRAPHY JOURNALS ONLINE}

Copyright (C) International Union of Crystallography

Author(s) of this paper may load this reprint on their own web site or institutional repository provided that this cover page is retained. Republication of this article or its storage in electronic databases other than as specified above is not permitted without prior permission in writing from the IUCr.

For further information see http://journals.iucr.org/services/authorrights.html 


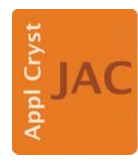

JOURNAL OF

APPLIED

CRYSTALLOGRAPHY

ISSN 1600-5767

Received 26 January 2018

Accepted 23 May 2018

Edited by G. Kostorz, ETH Zurich, Switzerland

Keywords: X-ray diffraction; operando characterization; stacking disorder; energy materials; lithium-ion batteries; structural refinement.

Supporting information: this article has supporting information at journals.iucr.org/j

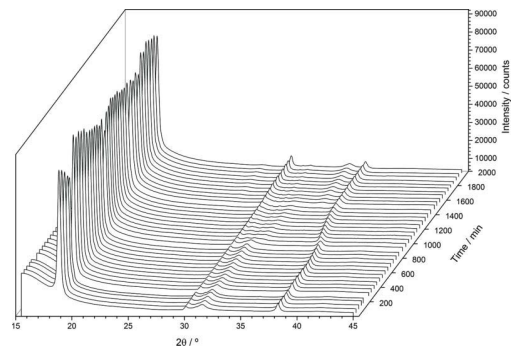

C 2018 International Union of Crystallography

\section{Intercalation of lithium into disordered graphite in a working battery}

\author{
Rune E. Johnsen, ${ }^{\mathrm{a} *}$ Poul Norby ${ }^{\mathrm{a}}$ and Matteo Leoni ${ }^{\mathrm{b}}$ \\ ${ }^{a}$ Department of Energy Conversion and Storage, Technical University of Denmark, Frederiksborgvej 399, Roskilde DK- \\ 4000, Denmark, and ${ }^{\mathbf{b}}$ Department of Civil, Environmental and Mechanical Engineering, University of Trento, via Mesiano \\ 77, Trento 38123, Italy. *Correspondence e-mail: runj@dtu.dk
}

The structural transformations occurring during the intercalation of lithium into disordered graphite in a working battery were studied in detail by operando X-ray powder diffraction (XRPD). By using a capillary-based micro-battery cell, it was possible to study the stacking disorder in the initial graphite as well as in lithiated graphites. The micro-battery cell was assembled in its charged state with graphite as positive electrode and metallic lithium as counter electrode. The battery was discharged until a stage II compound $\left(\mathrm{LiC}_{12}\right)$ was formed. The operando XRPD data reveal that the graphitic electrode material retains a disordered nature during the intercalation process. A DIFFaX+ refinement based on the initial operando XRPD pattern shows that the initial graphite generally has an intergrown structure with domains of graphite $2 \mathrm{H}$ and graphite 3R. However, the average stacking sequence of the initial graphite also contains a significant concentration of AA-type stacking of the graphene sheets. DIFFaX+ was further used to refine structure models of a stage III type compound and the final stage II compound. The refinement of the stage II compound showed that it is dominated by $\mathrm{A} \alpha \mathrm{AA} \alpha \mathrm{A}$-type stacking, but that it also contains a significant concentration of $\mathrm{A} \alpha \mathrm{AB} \beta \mathrm{B}$-type slabs in the average stacking sequence.

\section{Introduction}

Lithium-ion batteries (LIBs) are today crucial to the operation of most new commercial portable devices and electrical vehicles. An increased fundamental understanding of the electrochemical reactions and the structural and microstructural changes occurring in the electrode materials during battery operation is, however, still needed in order to be able to optimize the LIB technology even further. Graphite is used as the negative electrode material in the majority of the secondary Li-ion batteries produced today. It has been known for many years that lithium may intercalate into the graphite structure during charging of the battery. The intercalation causes an expansion of the basal spacing between the graphene sheets in the graphite structure (da Costa et al., 1994; Cryst \& McCusker, 1991; Xu et al., 2017). The maximum amount of lithium it is possible to intercalate into graphite is one lithium atom per six carbon atoms $\left(\mathrm{LiC}_{6}\right)$. This gives a theoretical specific capacity of $372 \mathrm{mAh} \mathrm{g}^{-1}$ for graphite as electrode material. Two polymorphs of well ordered graphite exist, graphite $2 \mathrm{H}$ and graphite $3 \mathrm{R}$, with hexagonal AB- (space group $\mathrm{P6}_{3} / \mathrm{mmc}$ ) and rhombohedral ABC-type (space group $R \overline{3} m$ ) stacking of graphene sheets, respectively. Graphite $2 \mathrm{H}$ is slightly more thermodynamically stable than graphite $3 \mathrm{R}$, but 
the energy difference is very small. Thus, most naturally occurring graphites have a disordered or intergrown structure with domains of graphite $2 \mathrm{H}$ and $3 \mathrm{R}$ stacked along a common $c$ axis (Shi, 1993; Shi et al., 1996; Herstedt et al., 2003; Dittrich \& Wohlfahrt-Mehrens, 2001). Several different lithiated graphite phases are formed as intermediates during the charging and discharging of the battery. $\mathrm{LiC}_{6}$ is, besides graphite, the most well described phase in the intercalation process. $\mathrm{LiC}_{6}$ is reported to crystallize in space group $P 6 / \mathrm{mmm}$, with a stacking sequence of $\mathrm{A} \alpha \mathrm{A} \alpha$ ( $\alpha$ denotes the position of the plane composed of the lithium atoms) (Guerard \& Herold, 1975; Kganyago \& Ngoepe, 2003). The degree of intercalation may also be associated with a stage number, which describes the number of graphene layers between two layers of intercalant. Thus, $\mathrm{LiC}_{6}$ is a stage I compound and $\mathrm{LiC}_{12}$ is a stage II compound. A series of other somewhat less well defined lithiated graphite phases, e.g. $\mathrm{LiC}_{36}, \mathrm{LiC}_{30}, \mathrm{LiC}_{27}, \mathrm{LiC}_{24}$ and $\mathrm{LiC}_{18}$, have also been reported (Dahn et al., 1990; Billaud \& Henry, 2002; Etacheri et al., 2011; Yao et al., 2004). These phases are sometimes grouped and referred to as part of the non-stoichiometric $\mathrm{Li}_{1-x} \mathrm{C}_{12}, \mathrm{Li}_{x} \mathrm{C}_{6}$ or $\mathrm{Li}_{x} \mathrm{C}$ phases. The relationship between the stage number and the chemical composition has generally been debated. $\mathrm{LiC}_{18}$ is occasionally called a stage III compound (Jiang et al., 1995), whereas others refer to it as a dilute stage II or stage $2 \mathrm{~L}$ compound with an in-plane ordering of one lithium atom per nine carbon atoms in the intercalated layer (Flandrois \& Simon, 1999; DiVincenzo et al., 1984; Billaud et al., 1996). The chemical composition of stage III is also suggested to be in the range of $\mathrm{LiC}_{25}-\mathrm{LiC}_{30}$ (Yao et al., 2004; Flandrois \& Simon, 1999). The chemical composition of stage IV is reported to be in the range from $\mathrm{LiC}_{24}$ to $\mathrm{LiC}_{44}$ LiC $_{50}$ (Flandrois \& Simon, 1999; Ohzuku et al., 1993). Regarding the space group of the intermediate phases, there seems to be an agreement in the literature that $\mathrm{LiC}_{12}$ crystallizes in $P 6 / \mathrm{mmm}$ with $\mathrm{A} \alpha \mathrm{AA} \alpha \mathrm{A}$-type stacking (Imai \& Watanabe, 2007; Woo et al., 1983; Guerard \& Herold, 1975; Billaud et al., 1996). The diluted stage II compound $\mathrm{LiC}_{18}$ is reported to have a stacking sequence of $\mathrm{A} \alpha \mathrm{AB} \beta \mathrm{B}$ (Woo et al., 1983; Billaud et al., 1996), with the suggested space group $P 6_{3} m c$ (Missyul et al., 2017). As for the stage III compound, the stacking sequence was suggested to be $\mathrm{A} \alpha \mathrm{ABA} \alpha \mathrm{ACA} \alpha \mathrm{A}$ or $\mathrm{A} \alpha \mathrm{ABA} \alpha \mathrm{ABA} \alpha \mathrm{A}$ (Billaud et al., 1996; Billaud \& Henry, 2002). Alternative models based on modulation mechanisms using a 'twist bilayer' approach have also been proposed to describe the ordering in $\mathrm{Li}_{x} \mathrm{C}_{6}(x<0.5)$ (Senyshyn et al., 2013).

In the present work, we study the intercalation of lithium into disordered graphite during discharging of a working battery with graphite as the positive electrode and metallic lithium as the negative electrode. Operando X-ray powder diffraction (XRPD) was used to study the structural transformations and refine changes in the stacking disorder of the graphitic electrode material using our capillary-based microbattery cell (Johnsen \& Norby, 2013). DIFFaX+ (Leoni et al., 2004) refinements provided valuable information about stacking sequences and stacking disorder in the disordered graphite and the lithiated graphites formed by electrochemical intercalation of lithium into a disordered graphite.

\section{Experimental details}

\subsection{Capillary-based micro-battery cell}

A micro-battery cell with a disordered graphite electrode was assembled according to the procedure described by Johnsen \& Norby (2013). A droplet of the electrode was dipcoated on the tip of a copper wire with a diameter of $0.15 \mathrm{~mm}$. A slurry of graphite (Fluka, product No. 78391), PVDF binder (polyvinylidene fluoride) and NMP ( $N$-methylpyrrolidone) was used for the dip-coating, resulting in a droplet with a diameter of approximately $0.6 \mathrm{~mm}$. A detailed description of the steps in the production of a capillary-based micro-battery cell is given by Johnsen \& Norby (2013).

\subsection{Operando X-ray powder diffraction}

Operando XRPD experiments were performed at beamline I711 at MAX-lab in Lund, Sweden. The micro-battery cell was placed in an electrical insulating sample holder frame and mounted on a goniometer head. The battery was connected to a Reference 600 Plus potentiostat from Gamry Instruments, which was used for galvanostatic discharge of a battery with a constant current of $5 \mu \mathrm{A}$ (the voltage was set to have a lower limit at $1 \mathrm{mV}$ ). Powder diffraction data were collected while discharging the micro-cell battery. The experimental setup used a Titan CCD detector from Oxford Diffraction (2048 $\times$ 2048 pixels) with a diameter of $165 \mathrm{~mm}$, a sample-to-detector distance of $73.01 \mathrm{~mm}$, a wavelength of $1.103 \AA$, a slit size of $0.2 \times 0.2 \mathrm{~mm}$ and an exposure time of $60 \mathrm{~s}$. The data were converted to conventional one-dimensional powder patterns using the program FIT2D (Hammersley, 2016).

2.2.1. Data analysis. TOPAS-Academic 4.1 (Coelho Software, Brisbane, Australia; http://www.topas-academic.net/; Coelho, 2018) was used to extract peak positions and halfwidth parameters. A pseudo-Voigt function was used to describe the peaks. DIFFaX+ (v2.500 Beta 10, 7 June 2010), which is based on the DIFFaX code (Treacy et al., 1991), was used to model and refine the disordered layered structures.

\section{Results and discussion}

The graphite/Li micro-battery cell was assembled in its charged state, where graphite is the positive electrode and lithium metal is the negative electrode. Fig. 1 shows the operando XRPD patterns of the graphite electrode as a function of time during the first galvanostatic discharge process. A relatively low discharging current of $5 \mu \mathrm{A}$ was chosen to minimize the risk of formation of chemical gradients in the graphite electrode material during the intercalation process. Previous studies have shown that a current of $5 \mu \mathrm{A}$ is sufficiently low to avoid long-range chemical inhomogeneity in the graphitic electrode material inside a micro-battery cell (Johnsen \& Norby, 2013). Fig. 1 reveals the apparent changes in the diffraction patterns of the graphitic electrode material as the intercalation reaction progresses during the discharging process. The diffraction patterns clearly show that the broad diffraction peaks of the pristine graphite compound are succeeded by other broad diffraction peaks of the different 


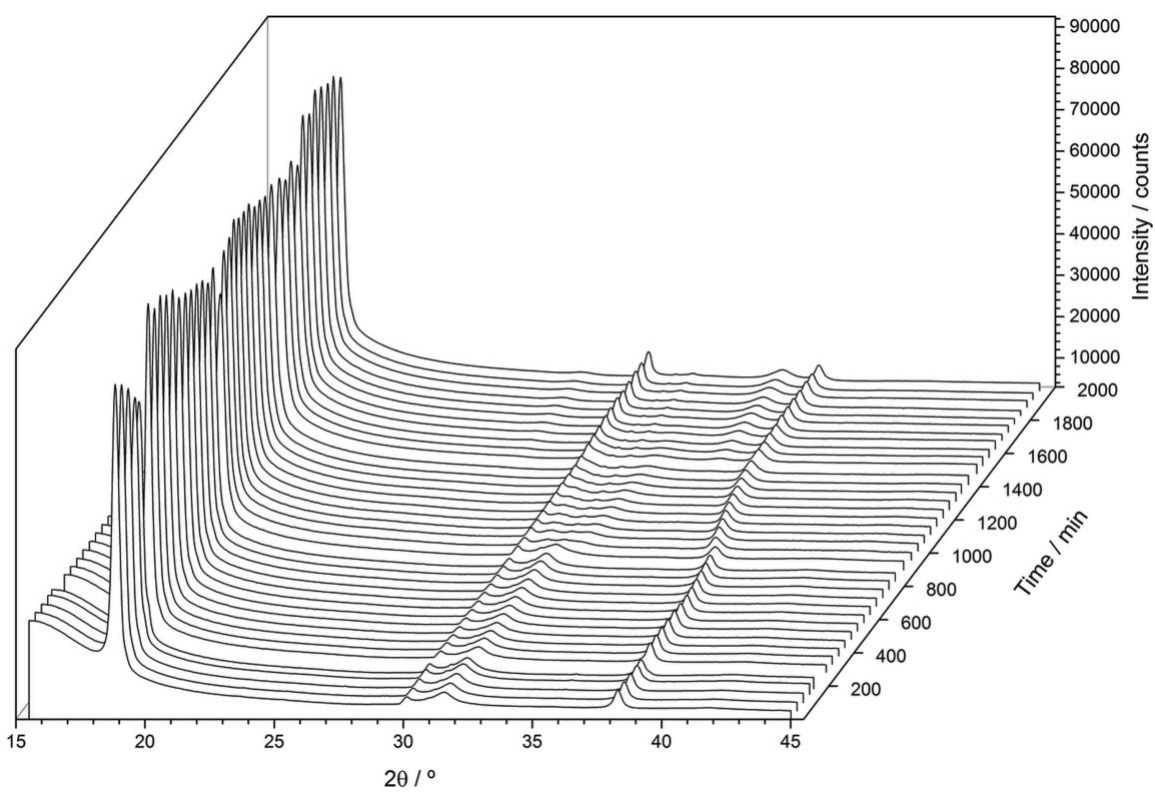

Figure 1

XRPD patterns of the graphitic electrode as a function of time during a galvanostatic discharge.

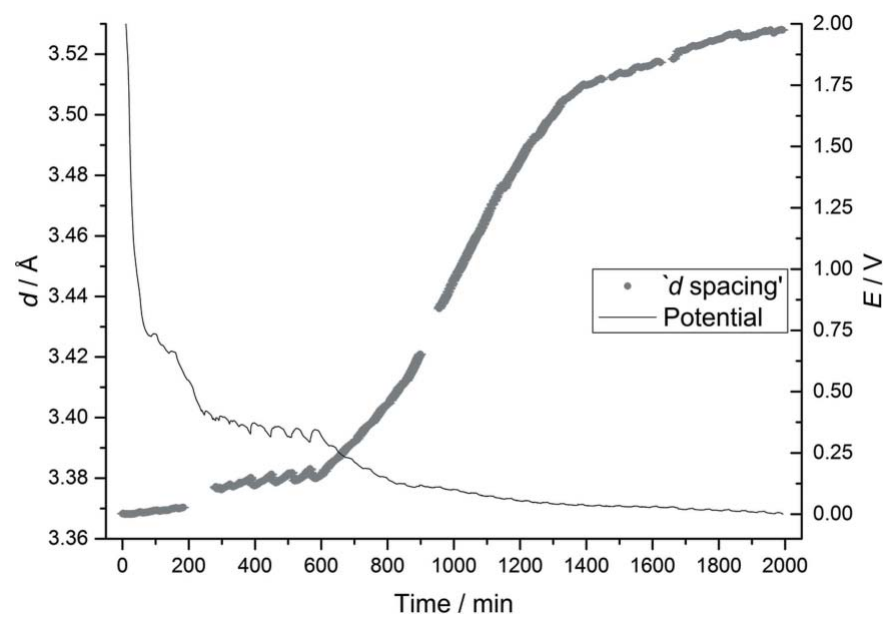

Figure 2

Changes in the ' $d$ spacing' of the ' $002_{2 \mathrm{H}}$ ' diffraction peak during a galvanostatic discharge. The ripples in the ' $d$ spacing' and potential curves are caused by instability in the power supply at MAX-lab.

lithiated graphite compounds. The broad characteristic of the diffraction peaks appears to be retained during the entire intercalation process. Fig. S1 (in the supporting information) shows the formation of a diffraction peak at a position corresponding to the position of the 001 reflection of $\mathrm{LiC}_{12}$ $(P 6 / \mathrm{mmm}, c \simeq 7.0 \AA)$ during the first galvanostatic discharge process.

The changes in the XRPD patterns were studied in detail using single-peak fitting as well as whole-pattern refinement of the data. Fig. 2 shows the changes in the cell potential and $d$ spacing values of the diffraction peak corresponding to the 002 diffraction peak of graphite $2 \mathrm{H}$ (and the 003 diffraction peak of graphite $3 \mathrm{R}$ ), at $2 \theta \simeq 18.5^{\circ}$, as a function of discharging time. The diffraction peak (reflecting the interplanar distance) is from now on referred to as the ' $002_{2 \mathrm{H}}$ ' peak, even though it strictly speaking has different indices for the different stages in the intercalation process. The ' $002_{2 \mathrm{H}}$ ' diffraction peak was treated as a single peak and described as a pseudo-Voigt function in the fitting process. The quotations marks around $d$ spacing in the legend of Fig. 2 indicate that this assumption may not be completely true in the entire discharging process, as will be discussed later. The gaps in the $d$ spacing curve are due to beam dumps in the storage ring of the synchrotron, and the ripples in the $d$-spacing values and potential curves are due to instability in the power supply at MAX-lab. Solid electrolyte interphase (SEI) layers are known to be formed at the graphite electrode during the first discharging process (or first charging process if graphite acts as negative electrode material) (Yamaguchi et al., 1998; Aurbach, 1995; Peled, 1998). The $d$ spacing does not usually change during the formation of the SEI layer for more well ordered graphite compounds as lithium is not intercalated into the graphite structure during the process. Thus, the small apparent increase in the $d$ spacing (shown in Fig. 2) could perhaps indicate that lithium does get intercalated into the structure of this disordered graphite. An operando XRPD study using an ECC-Opto-Std battery cell from EL-CELL $\mathrm{GmbH}$ with Fluka graphite as positive electrode material and metallic lithium as negative electrode material was conducted to elucidate the question further. The study shows that the $d$ spacing of the ' $002_{2 \mathrm{H}}$ ' diffraction peak is nearly constant during the formation of the SEI layer (Fig. S2 in the supporting information). Thus, the small apparent increase in the $d$ spacing of the graphite in the micro-battery cell is probably mainly related to the instability in the power supply at MAX-lab. The $d$ spacing starts to increase at a cell potential of approximately $0.65 \mathrm{~V}$ in the ECC-Opto-Std battery cell when the battery is being discharged very slowly.

The structure of the initial disordered graphite compound was studied in detail using DIFFaX+. A cell containing two graphene sheets was used for the DIFFaX+ refinement (Table 1). The second graphene sheet in the cell is stacked $(2 / 3,1 / 3)$ in the $a b$ plane with respect to the first sheet, giving an AB-type stacking of the graphene sheets in the cell. The cell is hexagonal $(a=b=2.4478, c=6.7120 \AA$ 吸 $\alpha=\beta=90, \gamma=$ $120^{\circ}$ ) but is described in the triclinic space group $P 1$. A threelayer model was used to refine the structure of the disordered graphite phase. The three layers are identical with a cell content as shown in Table 1 (Fig. S3 in the supporting information shows a sketch of the layers). Table 2 shows nine possible layer transition vectors for the three layers defined in Table 1, e.g. a $(0,0,1)$ stacking vector for the 1-1 layer transition. As the double layers in the cell are AB stacked, a stacking sequence with only 1-1-type stacking forms graphite $2 \mathrm{H}$, whereas 1-3-type stacking followed by 3-3-type stacking 
Table 1

Atomic coordinates, atomic displacement parameters and occupancy factors of the cell from the DIFFaX+ refinement of the initial graphite compound.

$a=2.4478, b=2.4478, c=6.7120 \AA, \alpha=90, \beta=90, \gamma=120^{\circ}$ (space group: $P 1$ ).

\begin{tabular}{llllll}
\hline Label & $x / a$ & $y / b$ & $z / c$ & $B_{\text {iso }}\left(\AA^{2}\right)$ & Occupancy \\
\hline $\mathrm{C} 1$ & 0 & 0 & $1 / 4$ & $2.30(7)$ & 1 \\
$\mathrm{C} 2$ & $1 / 3$ & $2 / 3$ & $1 / 4$ & $=B_{\text {iso }}(\mathrm{C} 1)$ & 1 \\
$\mathrm{C} 3$ & $2 / 3$ & $1 / 3$ & $3 / 4$ & $=B_{\text {iso }}(\mathrm{C} 1)$ & 1 \\
$\mathrm{C} 4$ & 1 & 1 & $3 / 4$ & $=B_{\text {iso }}(\mathrm{C} 1)$ & 1 \\
\hline
\end{tabular}

forms graphite 3R. A pseudo-Voigt function was used for the refinements over a $2 \theta$ range of $16.0-44.0^{\circ}$ using one refined half-width parameter $(W)$ and one fixed peak-shape parameter (the mixing parameter). The scale factor, the overall isotropic displacement parameter $\left(B_{\text {iso }}\right)$ and 12 Chebyshev background parameters were also refined, together with the seven stacking probabilities. The probability of 2-1- and 3-2type stacking was fixed to zero in order to reduce the complexity of the model. The refined stacking probabilities are shown in Table $2(t=1 \mathrm{~min})$. Fig. 3 shows the DIFFaX+ refinement plot of the initial disordered graphite. The asterisk symbol in the figure shows the position $\left(2 \theta \simeq 31^{\circ}\right)$ of a lowintensity diffraction peak originating from the 111 reflection of the copper current collector. The DIFFaX+refinement gave the following agreement factors: $R_{\mathrm{p}}=0.99 \%, R_{\mathrm{wp}}=1.39 \%$, $R_{\mathrm{p}}($ background $)=1.91 \%$ and $\mathrm{GOF}=1.40$.

The stacking probabilities from the DIFFaX+ refinement clearly show that the initial disordered graphite has an intergrown structure dominated by domains of both graphite $2 \mathrm{H}$ and graphite $3 \mathrm{R}$, but also that it contains sequences in the stacking of the graphene sheets that are different from those observed in graphite $2 \mathrm{H}$ and graphite $3 \mathrm{R}$. If one starts from layer one, there is a 10 (1)\% probability of having 1-2-type

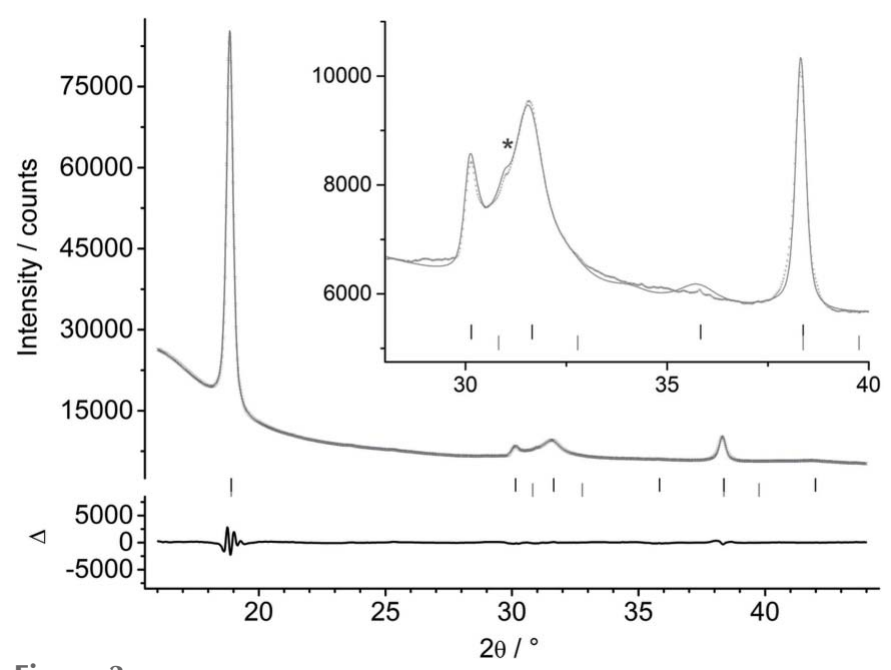

Figure 3

DIFFaX + refinement plot showing the experimental (black crosses), calculated (solid grey line) and difference (solid black line) profiles of the initial graphite compound $(t=1 \mathrm{~min})$. The black and grey vertical bars mark the positions of the Bragg reflections of the corresponding graphite $2 \mathrm{H}$ and $3 \mathrm{R}$ phases, respectively. The asterisk (*) symbol shows the position of the 111 diffraction peak of the copper current collector.
Table 2

Layer translation vectors and stacking probabilities of the DIFFaX+ refinement of the initial graphite compound $(t=1 \mathrm{~min})$.

\begin{tabular}{lllll}
\hline Layer transitions & $x / a$ & $y / b$ & $z / c$ & Probabilities \\
\hline $1-1$ & 0 & 0 & 1 & $0.67(3)$ \\
$1-2$ & $2 / 3$ & $1 / 3$ & 1 & $0.10(1)$ \\
$1-3$ & $1 / 3$ & $2 / 3$ & 1 & $0.23(1)$ \\
$2-1$ & 0 & 0 & 1 & 0 \\
$2-2$ & $2 / 3$ & $1 / 3$ & 1 & $0.52(7)$ \\
$2-3$ & $1 / 3$ & $2 / 3$ & 1 & $0.48(7)$ \\
$3-1$ & 0 & 0 & 1 & $0.60(2)$ \\
$3-2$ & $2 / 3$ & $1 / 3$ & 1 & 0 \\
$3-3$ & $1 / 3$ & $2 / 3$ & 1 & $0.40(2)$ \\
\hline
\end{tabular}

stacking which will form an ABBC stacking sequence of the individual graphene sheets. The stacking sequence contains BB-type stacking where the graphene sheets are stacked directly on top of each other, which forms a honeycomb structure with hexagonal prisms of carbon atoms. The BB-type stacking is on the local scale identical to AA-type stacking, which is expected when lithium is intercalated into graphite where A $\alpha$ A-type slabs are formed ( $\alpha$ denotes the position of the plane composed of $\mathrm{Li}$ atoms). Thus, one could imagine that it would be most energetically favourable for the intercalation of lithium atoms to start between the AA-type stacked graphene sheets. This would not require an in-plane sliding of the layers. If one starts from layer two, the probability of having 2-2-type stacking is 52 (7)\%, which will also on the local scale form an AA-type stacking of graphene sheets. A 1-2-type stacking followed by a 2-2-type stacking will form an ABBCCA stacking sequence of graphene sheets. Thus, the refined stacking probabilities indicate that the AAtype (AA, BB and $\mathrm{CC}$ ) stacking partly tends to cluster.

A previous study of intercalation of lithium in a more well ordered graphite revealed significant changes in the apparent full width at half-maximum (FWHM) of the ' $002_{2 \mathrm{H}}$ ' diffraction peak during charging and discharging of the micro-battery cell because of the coexistence of multiple phases (stages) (Johnsen \& Norby, 2013). Fig. S4 (in the supporting information) shows the changes in the apparent FWHM of the ' $002_{2 \mathrm{H}}$ ' diffraction peak of the disordered graphite during discharge of the battery. The changes in the apparent FWHM are relatively small, which indicates that the lithiated graphite very much retains a disordered nature. Thus, there is no indication of formation of well ordered lithiated graphite phases during the intercalation process. Also, the asymmetry of the ' $002_{2 \mathrm{H}}$ ' diffraction peak only changes slightly during the intercalation process.

DIFFaX + was also used to attempt to refine the structure of a 'stage III' compound with an interlayer spacing of approximately $3.48 \AA(t=1205 \mathrm{~min})$. A three-layer model where each of the cells consists of three layers of graphene and one layer of lithium was used for the refinement. The graphene layers are stacked $\mathrm{A} \alpha \mathrm{AB}, \mathrm{A} \alpha \mathrm{AC}$ and $\mathrm{BA} \alpha \mathrm{A}$ in the three cells, respectively (Fig. S3 in the supporting information shows a sketch of the layers). The cells are hexagonal ( $a=b=$ 2.456, $c=10.441 \AA, \alpha=\beta=90, \gamma=120^{\circ}$ ) but described in the triclinic space group $P 1$. The refinement is based on a 
Table 3

Atomic coordinates, atomic displacement parameters and occupancy factors of CELL1 from the DIFFaX+ refinement of the final stage II compound $(t=1976 \mathrm{~min})$.

$a=4.267, b=4.267, c=3.691 \AA$ А $\alpha=90, \beta=90, \gamma=120^{\circ}$ (space group: $P 1$ ).

\begin{tabular}{llllll}
\hline Label & $x / a$ & $y / b$ & $z / c$ & $B_{\text {iso }}\left(\AA^{2}\right)$ & Occupancy \\
\hline C1 & $1 / 3$ & 0 & 0 & $4.70(9)$ & 1 \\
C2 & $2 / 3$ & 0 & 0 & $=B_{\text {iso }}(\mathrm{C} 1)$ & 1 \\
$\mathrm{C} 3$ & 0 & $1 / 3$ & 0 & $=B_{\text {iso }}(\mathrm{C} 1)$ & 1 \\
$\mathrm{C} 4$ & 0 & $2 / 3$ & 0 & $=B_{\text {iso }}(\mathrm{C} 1)$ & 1 \\
$\mathrm{C} 5$ & $1 / 3$ & $1 / 3$ & 0 & $=B_{\text {iso }}(\mathrm{C} 1)$ & 1 \\
$\mathrm{C} 6$ & $2 / 3$ & $2 / 3$ & 0 & $=B_{\text {iso }}(\mathrm{C} 1)$ & 1 \\
$\mathrm{Li} 1$ & 0 & 0 & $1 / 2$ & $=B_{\text {iso }}(\mathrm{C} 1)$ & 1 \\
\hline
\end{tabular}

simplified model where lithium is statistically distributed within the $a b$ plane. Table S1 (in the supporting information) shows the layer transition vectors and the refined stacking probabilities for the refinement. Fig. 4 shows the DIFFaX+ refinement plot of the 'stage III' compound $(t=1205 \mathrm{~min})$. The DIFFaX+ refinement gave the following agreement factors: $R_{\mathrm{p}}=1.37 \%, R_{\mathrm{wp}}=2.12 \%, R_{\mathrm{p}}($ background $)=3.06 \%$ and $\mathrm{GOF}=2.16$. The sharper diffraction peak at $2 \theta \simeq 31.6^{\circ}$ in Fig. 4 originates from an impurity in the Fluka graphite, probably $\mathrm{SiC}$. The two-dimensional diffraction images from the area detector revealed the existence of diffraction spots from larger crystals at a $d$ value comparable to the position of the sharper diffraction peak. Fig. 4 shows that most of the features in the diffraction pattern (except for the diffraction peaks of the impurity and the current collector) are described by the refined structure model. Some of the estimated standard deviations of the refined stacking probabilities are relatively large (Table S1 in the supporting information). Thus, somewhat different structure models give more or less the same goodness of fit. However, the refinement does clearly demonstrate that slabs of $\mathrm{A} \alpha \mathrm{AB}$ and $\mathrm{A} \alpha \mathrm{AC}$ stacked directly

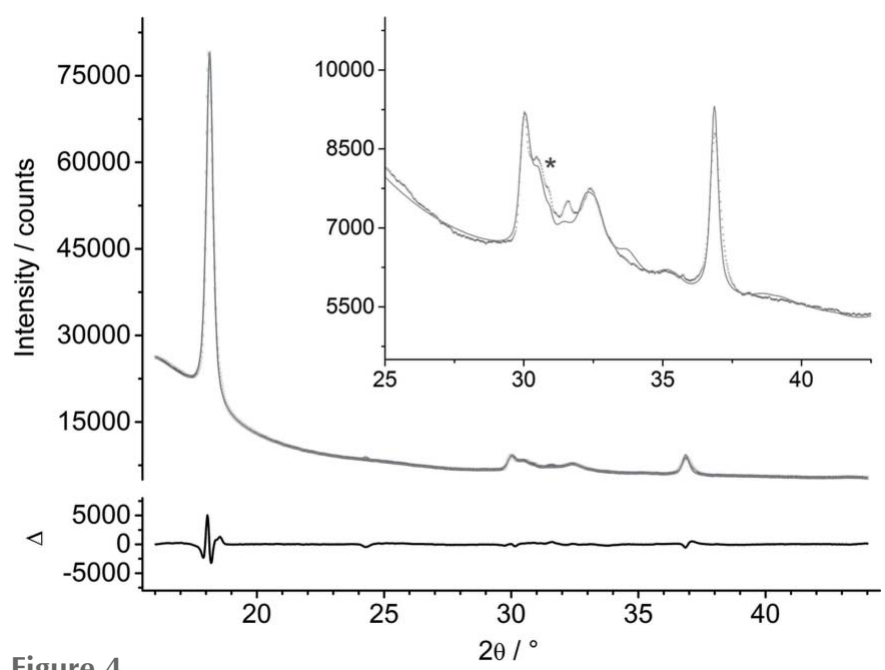

Figure 4

DIFFaX + refinement plot showing the experimental (black crosses), calculated (solid grey line) and difference (solid black line) profiles of a 'stage III' compound $(t=1205 \mathrm{~min})$. The asterisk (*) symbol shows the position of the 111 diffraction peak of the copper current collector.
Table 4

Layer translation vectors and stacking probabilities of the DIFFaX+ refinement of the final stage II compound $(t=1976 \mathrm{~min})$.

\begin{tabular}{lllll}
\hline Layer transitions & $x / a$ & $y / b$ & $z / c$ & Probabilities $\dagger$ \\
\hline $1-1$ & 0 & 0 & 1 & $0.02(1)$ \\
$1-2$ & 0 & 0 & 1 & $0.17(1)$ \\
$1-3$ & 0 & 0 & 1 & $0.81(2)$ \\
$2-1$ & $1 / 3$ & 0 & 0.9054 & 1 \\
$2-2$ & 0 & 0 & 0.9054 & 0 \\
$2-3$ & 0 & 0 & 0.9054 & 0 \\
$3-1$ & 0 & 0 & 0.9054 & $0.97(1)$ \\
$3-2$ & 0 & 0 & 0.9054 & 0 \\
$3-3$ & $1 / 3$ & 0 & 0.9054 & $0.03(1)$ \\
\hline
\end{tabular}

$\dagger$ The standard deviations are estimated manually.

on top of each other cannot fully describe the stacking disorder in this 'stage III' compound. A model that also included stage II and stage IV domains was needed. The slightly more asymmetric shape of the ' $002_{2 \mathrm{H}}$ ' diffraction peak supports the need to include the additional domains. The refinement shows that the structure is significantly more disordered than the 'stage III' compound in our previous study (Johnsen \& Norby, 2013), which was formed from a more well ordered graphite.

The structure of the final stage II compound was also studied using DIFFaX+. Two cells were used for the DIFFaX+ refinement: one cell (CELL1) containing one graphene layer and one layer of lithium with a chemical formula of $\mathrm{LiC}_{6}$ (Table 3), and one cell (CELL2) containing only one graphene layer (Table 3 minus the Li1 site). The cells are hexagonal ( $a=$ 4.267, $b=4.267, c=3.691 \AA, \alpha=90, \beta=90, \gamma=120^{\circ}$ ), but described in the triclinic space group $P 1$ (Fig. S3 in the supporting information shows a sketch of the layers). Lithium is ordered in-plane in CELL1 in order to avoid neighbouring prisms formed by carbon atoms in the A $\alpha$ A-type stacking being occupied by lithium at the same time. The repulsive forces are too high for lithium to occupy neighbouring prisms (Persson et al., 2010). A three-layer model was used for the refinement, where layer one has the chemical composition of CELL1 and layers two and three have the chemical composition of CELL2. Table 4 shows nine possible layer transition vectors for the three layers. A pseudo-Voigt function was used for the refinements over a $2 \theta$ range of $16.0-44.0^{\circ}$ using one refined half-width parameter $(W)$ and one fixed peak-shape parameter (the mixing parameter). The scale factor, the isotropic displacement parameter $\left(B_{\text {iso }}\right)$ and 12 Chebyshev background parameters were also refined, together with the five stacking probabilities. The probability of 2-2-, 2-3- and 3-2-type stacking was fixed to zero and the probability of 2-1 was fixed to one. The refined stacking probabilities are shown in Table $4(t=1976 \mathrm{~min})$. The table also shows that the $z$ component of the stacking vector along the $c$ axis is less than one for the layer transitions starting at layer two or three. This is because the interlayer spacing of two graphene sheets in graphite is approximately $90 \%$ of the spacing in an $\mathrm{A} \alpha \mathrm{A}$ stacking sequence. Fig. 5 shows the DIFFaX+ refinement plot of the stage II compound. The DIFFaX+ refinement gave the 


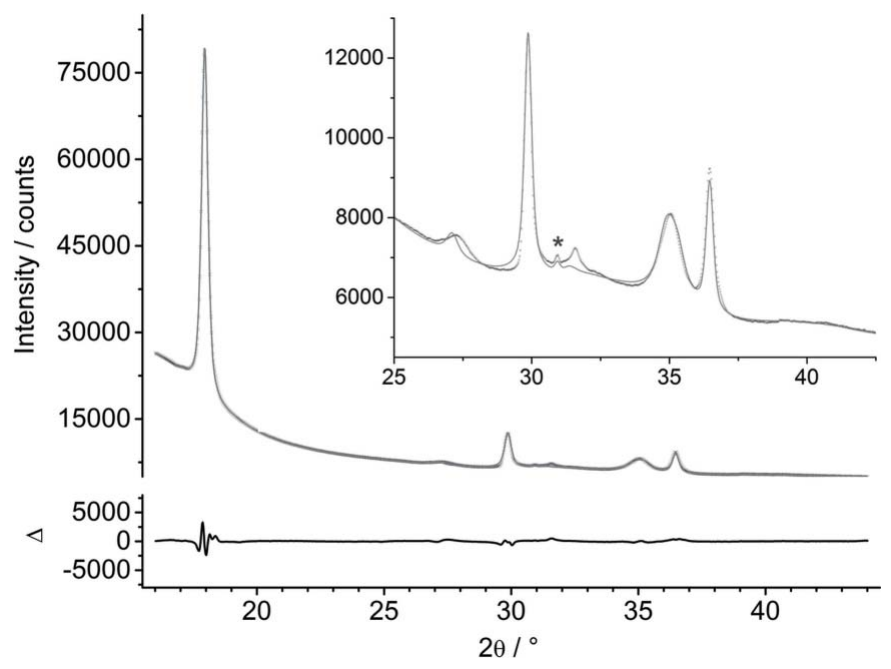

Figure 5

DIFFaX + refinement plot showing the experimental (black crosses), calculated (solid grey line) and difference (solid black line) profiles of the final stage II compound $(t=1976 \mathrm{~min})$. The asterisk $(*)$ symbol shows the position of the 111 diffraction peak of the copper current collector

following agreement factors: $R_{\mathrm{p}}=1.19 \%, R_{\mathrm{wp}}=1.78 \%$, $R_{\mathrm{p}}($ background $)=2.32 \%$ and $\mathrm{GOF}=1.80$.

A cycle of a 1-3 layer transition followed by a 3-1 layer transition will generate an $\mathrm{A} \alpha \mathrm{AA} \alpha \mathrm{A}$-type stacking sequence, which is the sequence that has been published for the stage II compound $\mathrm{LiC}_{12}$ (Guerard \& Herold, 1975; Woo et al., 1983; Billaud et al., 1996; Imai \& Watanabe, 2007). The refined stacking probabilities from the $D I F F a X+$ refinement clearly show that there is a high probability of having $\mathrm{A} \alpha \mathrm{AA} \alpha \mathrm{A}$ slabs in the stacking sequence. However, there is also a significant probability of having $\mathrm{A} \alpha \mathrm{AB} \beta \mathrm{B}$ slabs in the stacking sequence formed by a 1-2 layer transition followed by a 2-1 layer transition and a subsequent 1-2 or 1-3 layer transition. The refined stacking probabilities also suggest that the average stacking sequence contains a low concentration of small domains of stage I formed by the 1-1 layer transition. Furthermore, the refined stacking probabilities indicate the existence of small stage III domains formed by a sequence of 1-3, 3-3 and 3-1 layer transitions. Thus, the final stage II compound also displays a disordered nature with a significant amount of stacking disorder, including low concentrations of stage I and stage III domains in the stacking sequence.

\section{Conclusion}

This operando XRPD study of the structural transformations occurring during intercalation of lithium into disordered graphite in a working $\mathrm{Li}-\mathrm{C}$ battery revealed that the graphitic electrode material retained a disordered nature during the intercalation process. By using our specially designed capillary-based micro-battery cell, it was possible to study the stacking order/disorder in the initial graphite as well as in lithiated graphites. The micro-battery cell was assembled in its charged state and discharged until a stage II compound $\left(\mathrm{LiC}_{12}\right)$ was formed. The DIFFaX+ refinement based on the initial operando XRPD pattern showed that the initial disordered graphite had an intergrown structure dominated by domains of graphite $2 \mathrm{H}$ and graphite $3 \mathrm{R}$, but also that it contained sequences in the stacking of the graphene sheets different from those observed in graphite $2 \mathrm{H}$ and graphite $3 \mathrm{R}$. For example, there was a 10 (1)\% probability of having 1-2type stacking forming an ABBC-type slab of graphene sheets. Thus, the initial graphite also contains a significant concentration of AA-type stacking of the graphene sheets. The $D I F F a X+$ refinement of the 'stage III' compound showed that slabs of $\mathrm{A} \alpha \mathrm{AB}$ and $\mathrm{A} \alpha \mathrm{AC}$ stacked directly on top of each other could not fully describe the stacking disorder. A model that included stage II and stage IV domains was needed for the refinement. DIFFaX+ was also used to refine the structure model of the final stage II compound. The refinement showed that the stage II compound was dominated by $\mathrm{A} \alpha \mathrm{AA} \alpha \mathrm{A}$-type stacking, but that it also contained a significant concentration of $\mathrm{A} \alpha \mathrm{AB} \beta \mathrm{B}$-type slabs in the average stacking sequence.

\section{Acknowledgements}

The authors would like to acknowledge Anders W. Jensen for assisting in the assembling of the micro-battery cell. The staff of beamline I711 at MAX-lab, Sweden, are gratefully acknowledged for experimental assistance.

\section{Funding information}

The research leading to these results has received funding from the European Union's Seventh Framework Programme (FP7/2007-2013) under grant agreement 608575. DANSCATT is acknowledged for covering travel expenses in relation to the synchrotron experiment.

\section{References}

Aurbach, D. (1995). J. Electrochem. Soc. 142, 2882-2890.

Billaud, D. \& Henry, F. (2002). Solid State Commun. 124, 299-304.

Billaud, D., Henry, F., Lelaurain, M. \& Willmann, P. (1996). J. Phys. Chem. Solids, 57, 775-781.

Coelho, A. A. (2018). J. Appl. Cryst. 51, 210-218.

Costa, G. M. da, De Grave, E., de Bakker, P. M. A. \& Vandenberghe, R. E. (1994). J. Solid State Chem. 113, 405-412.

Dahn, J., Fong, R. \& Spoon, M. (1990). Phys. Rev. B, 42, 6424-6432.

Dittrich, H. \& Wohlfahrt-Mehrens, M. (2001). Int. J. Inorg. Mater. 3, 1137-1142.

DiVincenzo, D., Fuerst, C. \& Fischer, J. (1984). Phys. Rev. B, 29, 1115.

Etacheri, V., Marom, R., Elazari, R., Salitra, G. \& Aurbach, D. (2011). Energ. Environ. Sci. 4, 3243-3262.

Flandrois, S. \& Simon, B. (1999). Carbon N. Y. 37, 165-180.

Guerard, D. \& Herold, A. (1975). Carbon N. Y. 13, 337-345.

Hammersley, A. P. (2016). J. Appl. Cryst. 49, 646-652.

Herstedt, M., Fransson, L. \& Edström, K. (2003). J. Power Sources, 124, 191-196.

Imai, Y. \& Watanabe, A. (2007). J. Alloys Compd. 439, 258-267.

Jiang, Z., Alamgir, M. \& Abraham, K. M. (1995). J. Electrochem. Soc. 142, 333-340.

Johnsen, R. E. \& Norby, P. (2013). J. Appl. Cryst. 46, 1537-1543.

Kganyago, K. \& Ngoepe, P. (2003). Phys. Rev. B, 68, 205111.

Leoni, M., Gualtieri, A. F. \& Roveri, N. (2004). J. Appl. Cryst. 37, 166-173.

McCusker, L. B. (1991). Acta Cryst. A47, 297-313. 
Missyul, A., Bolshakov, I. \& Shpanchenko, R. (2017). Powder Diffr. 32, S56-S62.

Ohzuku, T. et al. (1993). J. Electrochem. Soc. 140, 2490-2498.

Peled, E. (1998). J. Electrochem. Soc. 145, 3482-3486.

Persson, K., Hinuma, Y., Meng, Y. S., Van der Ven, A. \& Ceder, G. (2010). Phys. Rev. B, 82, 125416.

Senyshyn, A., Dolotko, O., Muhlbauer, M. J., Nikolowski, K., Fuess, H. \& Ehrenberg, H. (2013). J. Electrochem. Soc. 160, A3198A3205.

Shi, H. (1993). PhD thesis, Simon Fraser University, Canada.

Shi, H. et al. (1996). J. Electrochem. Soc. 143, 3466-3472.
Treacy, M. M. J., Newsam, J. M. \& Deem, M. W. (1991). Proc. R. Soc. London Ser. A, 433, 499-520.

Woo, K., Kamitakahara, W., DiVincenzo, D. P., Robinson, D. S., Mertwoy, H., Milliken, J. W. \& Fischer, J. E. (1983). Phys. Rev. Lett. 50, 182-185.

Xu, J., Dou, Y., Wei, Z., Ma, J., Deng, Y., Li, Y., Liu, H. \& Dou, S. (2017). Adv. Sci. 4, 1700146.

Yamaguchi, S., Asahina, H., Hirasawa, K. A., Sato, T. \& Mori, S. (1998). Mol. Cryst. Liq. Cryst. Sci. Technol. Sect. A Mol. Cryst. Liq. Cryst. 322, 239-244.

Yao, T. et al. (2004). Solid State Ionics, 175, 199-202. 